MEDICAL PRACTICE

\title{
Survey of general practitioners' attitudes to management of patients with heart attacks
}

\author{
J R HAMPTON， G KEITH MORRIS，CHRISTINE MASON
}

British Medical fournal, 1975, 4, 146-148

\section{Summary}

Out of 305 general practitioners sent a questionnaire asking how they would treat three hypothetical patients with heart attacks $231(76 \%)$ replied. Of these, only 179 were prepared to make an unqualified choice of home or hospital treatment for a middle-aged man with an uncomplicated attack, $70(39 \%)$ saying that they would keep the patient at home. Practitioners qualifying before 1960 were more likely to do this than those qualifying in 1960 or later. If a patient declined hospital treatment $161(70 \%)$ of the practitioners would keep him in bed for a week or less, but the date of the practitioners' qualification significantly affected the time they would advise him to remain off work. Faced with a patient acutely ill after a heart attack, $162(70 \%)$ of the practitioners would arrange his immediate admission to hospital and $51(22 \%)$ would send him to hospital after initial treatment at home.

The numbers of partners in the practice, the nature of the premises, and the location of the practice in urban or rural areas affected the practitioners' attitude to the management of severely ill patients but not to the management of patients with uncomplicated attacks.

University Department of Medicine, General Hospital, Nottingham NG1 6HA

J R HAMPTON, DM, FRCP, consultant physician and reader in medicine G KEITH MORRIS, MB, MRCP, lecturer in medicine

Department of Community Health, Nottingham University, Nottingham

CHRISTINE MASON, MA, BSC, research associate (now lecturer in medical sociology, Department of Community and Occupational Medicine, University of Dundee)

\section{Introduction}

There is considerable doubt whether patients with heart attacks should be cared for at home or in hospital. The only large, published study ${ }^{1}$ suggested that the mortality in un complicated cases was slightly lower when the patients remained at home. Certain aspects of that study were open to criticism, but in the present state of knowledge a general practitioner may feel that it is in his patient's best interest to keep him at home. The attitudes of general practitioners near a district general hospital will affect the demand for beds in a coronary care unit, and it is difficult to plan new units without taking into account the number of patients who will be cared for at home.

There is also doubt about the ideal period of bed rest after myocardial infarction, and although controlled trials have shown periods as short as 48 hours to be adequate for patients in hospital who have no complications, ${ }^{2}$ it is not known whether general practitioners mobilise the patients they keep at home equally rapidly.

We have tried to discover the attitudes of general practitioners in the areas surrounding Nottingham General Hospital to the management of patients with heart attacks in terms of home or hospital care, recommended periods of bed rest and inactivity, and recommended time for return to work.

\section{Methods}

Questionnaires were sent to the 305 general practitioners in the City of Nottingham and the surrounding areas served by Nottinghan General Hospital. Altogether 231 completed forms (76\%) werc returned. The practitioners could remain anonymous if they so wished, and 35 did not sign the forms.

The questionnaires were in two parts. Firstly, the practitioners were asked basic details about themselves and their practices. They were asked to give their year of qualification; to say whether they considered their practice to be primarily urban, primarily rural, or mixed; to give the number of partners in their practice; and to state whether they were based in a local authority health centre or a purpose-built health centre other than one provided by the local authority or neither of these. 
In the second part of the questionnaire the practitioners' attitude to the management of patients was assessed by asking how they would manage three hypothetical patients, whose case histories were given. In each case questions were asked and a number of alternative replies given; only one could be selected. The three case histories were intended to represent patients with an apparently uncomplicated heart attack, with the intention of finding out the practitioner's attitude to home or hospital treatment; an uncomplicated attack but with the patient refusing hospital admission, so that the practitioner had to define his attitude to bed rest, mobilisation, and return to work; and a heart attack complicated by hypotension and left ventricular failure. In each case the patient was a middle-aged man with good social circumstances. A letter was sent with the questionnaire emphasising that there were no "correct" answers.

\section{Practitioners and practices}

Table I gives the years of qualification of the practitioner who completed the questionnaire. Altogether $125(54 \%)$ said that their practices were primarily urban, $35(15 \%)$ that they were primarily rural, and $71(31 \%)$ that they were mixed. Thirty-nine of the practitioners $(17 \%)$ worked single-handed, $72(31 \%)$ worked in practices of two partners, $62(27 \%)$ worked in practices of three partners, and $58(25 \%)$ worked in partices of four or more partners. Forty-two of the respondents $(18 \%)$ worked in local authority health centres, $49(21 \%)$ in other health centres, and $140(61 \%)$ in other types of premises. The proportion of health centres among urban, rural, and mixed practices was similar, and in the health centres there were several singlehanded and two-man practices.

TABLE I-Y oar of qualification of the 231 general practitioners who roplied to questionnaire

\begin{tabular}{l|c|c|c|c|c|c|c|c|c|c|c}
\hline $\begin{array}{l}\text { Year } \\
\text { qualified }\end{array}$ & $1920-4$ & $25-$ & $30-$ & $35-$ & $40-$ & $45-$ & $50-$ & $55-$ & $60-$ & $65-$ & $70-$ \\
No of GPs & 2 & 4 & 4 & 23 & 31 & 33 & 37 & 39 & 31 & 24 & 3 \\
\hline
\end{tabular}

\section{Answers to questions on hypothetical patients}

\section{FIRST HYPOTHETICAI. CASE}

The first history was intended to represent a patient who appeared to have a straightforward heart attack, and the practitioner was asked to choose between only two alternatives.

A 45-year-old man who lives in good social circtimstances calls you because of sudden chest pain which is typical of a heart attack. He is obviously in pain but his blood pressure and cardiac rhythm are normal and he is not in heart failure.

Would you $(A)$ admit him to hospital, or $(B)$ look after him at home?

Only 179 practitioners gave an unqualified answer to this question, $109(61 \%)$ opting for hospital admission, and $70(39 \%)$ saying that they would look after the patient at home. There was a significant difference $(P<0.02)$ between the choices made by practitioners of different ages: of the 136 who qualified before 1960,77 $(57 \%)$ said that they would send the patient to hospital, while of the 43 who qualified in 1960 or later $33(77 \%)$ gave preference for hospital admission. There were no significant differences between the choices made by practitioners in urban as opposed to rural or mixed urban and rural areas, nor were there any differences between members of small and of large practices or between those who worked in health centres and in other accommodation.

\section{SECOND HYPOTHETICAL CASE}

This case again presented the problem of a patient with an uncomplicated heart attack, but as the patient refused hospital admission the general practitioner had to decide on his method of management at home. Questions were asked about the period of bed rest, timing of mobilisation, and time off work. An attempt was also made to find whether the practitioner altered his management according to the patient's occupation.

A 45-year-old company director has seen you twice in the past six months complaining of central chest pain which radiates to the left arm and is brought on by exercise and relieved by rest and trinitrin. He calls you because he has a similar but more severe pain which developed at rest and has persisted for an hour despite trinitrin. You find him apprehensive, sweating, and in considerable pain. His pulse is regular at 110 per minute, his blood pressure is $140 / 90$, and there are no signs of heart failure. He refuses to be admitted to
TABLE II-Second hypothetical case. Time after pain had settled that general practitioner woula allow patient out of bed

\begin{tabular}{|c|c|c|c|c|c|c|c|}
\hline \multirow[b]{2}{*}{ Time after pain had settled: } & \multicolumn{3}{|c|}{ Hours } & \multicolumn{4}{|c|}{ Days } \\
\hline & 0 & 24 & 48 & 5 & 7 & 14 & 21 \\
\hline No $(\%)$ of GPs & $1(0.4)$ & $11(5)$ & 40 (17) & $34(15)$ & $75(32)$ & $52(23)$ & $18(8)$ \\
\hline
\end{tabular}

TABLE III-Second hypothetical case. Time after pain had settled that general practitioner would allou patient to begin going out of his house

\begin{tabular}{|c|c|c|c|c|c|c|c|c|}
\hline \multirow[b]{2}{*}{ Time after pain had settled: } & \multicolumn{3}{|c|}{ Hours } & \multicolumn{5}{|c|}{ Days } \\
\hline & 0 & 24 & 48 & 5 & 7 & 14 & 21 & 28 \\
\hline No $(\%)$ of GPs & 0 & $1(0.4)$ & $1(0.4)$ & $5(2)$ & $24(10)$ & $66(29)$ & $62(27)$ & $72(31)$ \\
\hline
\end{tabular}

TABLE IV-Time after uncomplicated heart attack (second hypothetical case) that general practitioners would recommend office worker and manual worker to return to work. Results expressed as proportions of GPs

\begin{tabular}{|c|c|c|c|c|c|c|c|}
\hline Weeks after attack: & 1 & 2 & 3 & 4 & 6 & 8 & 12 \\
\hline $\begin{array}{l}\text { Manual worker } \\
\text { Office worker .. }\end{array}$ & $\begin{array}{l}0 \\
0\end{array}$ & $2(1 \%)$ & $6(3 \%)$ & $\begin{array}{r}4(2 \%) \\
35(15 \%)\end{array}$ & $\begin{array}{l}31(13 \%) \\
77(33 \%)\end{array}$ & ) & $\begin{array}{r}148(64 \%) \\
45(19 \%)\end{array}$ \\
\hline
\end{tabular}

hospital, and an E.C.G. confirms that he has had a myocardial infarction. Within 24 hours he is free of pain and his course thereafter is completely uncomplicated.

(1) When would you allow him out of bed?

Seven choices were given: immediately the patient was free of pain, 24 hours after the pain had settled, 48 hours after the pain had settled, and $5,7,14$, and 21 days after the pain had settled. Table II gives the proportion of practitioners selecting each of these. Fifty-two of them $(23 \%)$ would have had the patient out of bed within 48 hours after the pain had settled, and $161(70 \%)$ within a week; only $18(8 \%)$ felt that at least three weeks in bed was necessary.

The date of qualification of the practitioner had a less marked effect on his attitude to bed rest than on his attitude to hospital admission. Just over a third of each of the groups who qualified between 1920 and 1939,1940 and 1959, and after 1960 chose to keep their patient in bed for five days or less. Nevertheless, whereas $47(34 \%)$ of those qualifying between 1940 and 1959 opted for two or more weeks of bed rest, only $8(24 \%)$ of those who qualified before 1940 and $14(24 \%)$ of those qualifying after 1960 thought that two or more weeks in bed was necessary after the pain had settled.

Neither the location of the practice-urban or rural-nor its size nor the nature of the practice premises had a significant effect on the practitioner's attitude to bed rest.

(2) When would you allow him to begin going out of his house?

Table III gives the proportion of practitioners who selected each of the choices given. Altogether $134(58 \%)$ would have confined the patient to his house for three weeks or more, and the response was much the same whenever the practitioner qualified. Again neither the type nor size of the practice nor the nature of the premises bore any relation to the practitioner's choice.

(3) When would you allow him to return to work?

The modal time chosen for the company director's return to work was six weeks after his attack (table IV). The effect of the practitioner's date of qualification was greater here than on the time the patient was confined to bed : $15(45 \%)$ of those qualifying before 1940 and $26(45 \%)$ of those qualifying after 1960 would have kept the patient off work for eight weeks or more, whereas $96(69 \%)$ of those qualifying between 1940 and 1959 opted for this length of time off work. This difference between groups of practitioners is significant $(P<0.05)$ but the location of the practice, the number of partners, and the type of practice premises bore no relation to the practitioner's choice.

(4) If this patient had been a heavy manual worker rather than a company director when would you allow him to return to work?

Altogether $148(64 \%)$ of the practitioners believed that at least three months off work would have been necessary for such a patient. A similar response was given by all groups of practitioners, and as no longer option was given in the questionnaire further analysis was not possible.

\section{THIRD HYPOTHETICAL CASE}

This problem was that of a patient who was obviously extremely ill after a heart attack and who might possibly be considered "too ill to 
move." The main aim was to see whether such circumstances would influence the practitioners' attitudes to home or hospital treatment. A supplementary question was posed to assess the practitioners' views of the desirability of retiring from work.

A 45-year-old company director had myocardial infarctions five and two years ago. You are called because he has had a severe attack of pain, and you find him propped up in bed, cold and sweating, and extremely breathless. His pulse is rapid and difficult to count, his blood pressure is unrecordable, and you are unable to hear his heart because of pulmonary oedema.

Would you $(A)$ treat the pain and pulmonary oedema and keep him at home; $(B)$ arrange immediate admission to hospital; or $(C)$ keep him at home for 24-48 hours until he began to respond to treatment and then arrange for his admission?

Eighteen of the practitioners $(8 \%)$ opted for home management, $162(70 \%)$ for immediate hospital admission, and $51(22 \%)$ for delayed hospital admission. The year of the practitioner's qualification seemed to affect his choice, although in the opposite direction to that in the first case. None of the practitioners who qualified before 1940 selected home management, whereas $11(8 \%)$ of those qualifying between 1940 and 1959 and $6(11 \%)$ of those qualifying after 1960 did so. The proportion selecting delayed hospital admission was closely similar in each of these groups, being $6(18 \%), 32(23 \%)$, and $13(22 \%)$ respectively. Only $4(3 \%)$ of the doctors working in urban or suburban areas would have treated the patient at home, whereas $8(11 \%)$ of those in mixed urban and rural practices and $5(14 \%)$ of those in rural practices would have done so.

There was a trend for those working in the larger practices to prefer home management : $2(5 \%)$ of those in single-handed practices selected home treatment compared with $8(6 \%)$ of those in two- and three-man practices and $8(14 \%)$ of those who worked in practices with four or more partners. Six $(14 \%)$ of those working in a local authority health centre and $5(10 \%)$ of those in a purpose-built but not local authority health centre selected home treatment but only $7(5 \%)$ of those not working in a health centre did so.

He makes a slow recovery and a month later is still breathless after walking a few hundred yards, and he gets angina when walking in cold or windy weather. $\mathrm{He}$ is, however, keen to return to work.

Would you $(A)$ allow him to return to work; $(B)$ anticipate that he will return to work in a further month; $(C)$ anticipate that he will return to work in a further two months; or $(D)$ advise him to retire?

Fourteen of the practitioners $(6 \%)$ indicated that they would allow the patient to return to work, $51(23 \%)$ anticipated that he would need a further month off work, and $122(53 \%)$ anticipated a further twomonths of convalescence. Only $44(19 \%)$ said that they would recommend that the patient retire. There were no significant differences between the choices made by practitioners who had qualified at different times, who worked in different types of locality, or who worked in different-sized practices.

\section{Discussion}

Estimates of the number of coronary care beds required for a population of 250000 vary from $5.1^{3}$ to $10,^{4}$ but clearly the demand for such beds depends largely on the preferences of general practitioners for home or hospital treatment. It has been suggested that if a general practitioner sees a patient with chest pain of more than two hours' duration he may as well keep him at home, ${ }^{5}$ and practitioners opting for home management of patients with uncomplicated attacks can claim justification' even though ideal trials of the two forms of treatment have yet to be completed. Nevertheless, we were surprised to find that 70 $(39 \%)$ of the practitioners in areas surrounding Nottingham General Hospital said that they would keep a middle-aged man with an uncomplicated heart attack (first hypothetical case) at home. Our questionnaire did not disclose why practitioners who qualified before 1960 should be more likely to opt for home management, but it may be that this reflects their training in the era before coronary care units came into being.

The relatively short duration of bed rest one week or less) that $161(70 \%)$ ) of the practitioners advised for the patient who declined admission to hospital (second hypothetical case) is in line with trials of early mobilisation that had been described up to the time of our survey. ${ }^{6}$ Though practitioners qualifying after 1960 tended to prefer hospital treatment, this group clearly believed in early mobilisation more than their senior partners who qualified between 1940 and 1959. Interestingly, the practitioners qualifying before 1940 also tended to disapprove of long periods of bed rest, but their reasons are a matter for speculation. The wide variation in the amount of bed rest prescribed was striking (one of the practitioners would have allowed the patient up immediately the pain had settled, whereas 18 prescribed three or more weeks of bed rest) but not surprising; in a comparable study of the habits of physicians admitting patients with infarctions to a single American hospital the mean duration of bed rest prescribed by different doctors for the uncomplicated cases ranged from 7.4 to 15.2 days. ${ }^{7}$

Surveys conducted in the UK, ${ }^{8}$ the USA, ${ }^{\circ}$ and Sweden ${ }^{10}$ have shown that after a myocardial infarction manual workers have longer periods off work and tend to change their jobs and to retire more readily than office workers. Wincott and Caird ${ }^{11}$ showed that there was no apparent difference in the severity of the attack between patients off work for more than three months and those who had returned to work in this time and attributed the difference between groups, at least in part, to differences in the attitudes of general practitioners. It is clear from our survey that most practitioners believe that manual workers need a prolonged convalescence after a myocardial infarction, even though there is little firm evidence to support this view.

The replies to questions about the patient who might have been considered "too ill to move" (third hypothetical case) showed that few practitioners believed that the difficulties and dangers of an ambulance journey outweighed the possible benefits of hospital treatment for the seriously ill patient. It is perhaps for this group of patients that the hospital has least to offer, and possibly it is in this group that the stress of transfer carries the highest risk. It was only with this category of patient that there was any apparent difference between the attitudes of practitioners in urban and rural areas, but even so $21(66 \%)$ of the rural doctors chose immediate hospital admission for this patient. The reasons for the practitioners' choices are not clear, although it seemed from remarks written below this question that at least some practitioners felt that the relatives expected hospital admission if the patient was very ill and feared that their standing in the community might be affected if a man with a myocardial infarction died at home.

Our survey can only reflect the attitudes of practitioners in one area at one point in time and we cannot be certain that the attitudes expressed in a questionnaire accurately reflect behaviour. It appears, however, that there may be many patients in Nottingham who are not at present admitted to hospital with heart attacks, and there could be a marked change in the hospital work load at any time if something were to change the attitudes of local general practitioners. There is clearly still a need for trials to elucidate many aspects of the care of patients with myocardial infarction; the only phase of the illness in which treatment is relatively well defined concerns the duration of bed rest in hospital. ${ }^{2}$ Whether or not particular categories of patient should be kept at home or sent to hospital remains unknown, and it is also not clear how long survivors should remain off work.

We are extremely grateful to the general practitioners who completed the questionnaires, and to $\operatorname{Dr} \mathrm{D}$ Metcalfe, of the department of community health at Nottingham University, for help and cooperation.

\section{References}

1 Mather, H G, et al, British Medical fournal, 1971, 3, 334

2 Hayes, M J, Morris, G K, and Hampton, J R, British Medical fournal, 1974, 2, 10.

3 Smyllie, H C, Taylor, M P, and Cuninghame-Green, R A, British Medical fournal, 1972, 1, 31 .

4 World Health Organization, Organisation of Coronary Care Units. Copenhagen, WHO Regional Office for Europe, 1960

5 Colling, A, British Medical fournal, 1974, 1, 559.

${ }^{6}$ Harpur, J E, et al, Lancet, 1971, 2, 1331.

7 Duke, M, American Heart fournal, 1971, 82, 486

8 Sharland, D E, British Medical fournal, 1964, 2, 718

9 Shapiro, S, Weinblatt, E, and Frank, C, Archives of Environmental Health, 1972, 24, 17.

10 Biorch, G, and Wedelin, E, Acta Medica Scandinavica, 1964, 175, 215.

11 Wincott, E A, and Caird, F I, British Medical fournal, 1966, 2, 1302. 